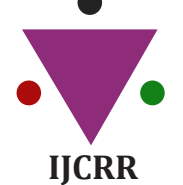

Section: Healthcare

Sci. Journal Impact

Factor: 6.1 (2018)

ICV: 90.90 (2018)

(c) (i) (3)

Copyright@IJCRR

\title{
Childhood Urinary Tract Infection: Prevalence and Resistance Pattern of Uropathogens in a Tertiary Care Hospital
}

\section{Suren Kumar Das' ${ }^{1}$ Purabi Baral'2, Swati Jain², Rajashree Panigrahy ${ }^{3}$}

\begin{abstract}
'Professor \& HOD, Department of Urology, IMS and SUM Hospital, Siksha "O" Anusandhan University (Deemed to be), K8 Kalinga Nagar, Bhubaneswar-751003, Odisha, India; 'Assistant Professor, Department of Microbiology, IMS and SUM Hospital, Siksha "O" Anusandhan University (Deemed to be), K8 Kalinga Nagar, Bhubaneswar-751003, Odisha, India; 3Professor, Department of Microbiology, 1MS and SUM Hospital, Siksha "O" Anusandhan University (Deemed to be), K8 Kalinga Nagar, Bhubaneswar-751003, Odisha, India.
\end{abstract}

\section{ABSTRACT}

Background: Urinary tract infection is one of the most common bacterial infections encountered by paediatricians. Currently, the diagnosis and management of acute urinary tract infection and recurrent urinary tract infection in children remains controversial. Prompt diagnosis and initiation of treatment are important in preventing long-term renal scarring. However, increasing antibiotic resistance may delay the initiation of appropriate therapy. Antibiotic prophylaxis remains controversial.

Objective: To identify the bacterial pathogens involved in pediatric UTI and study their antibiogram patterns.

Methods: A total of 1492 urine samples of pediatric patients (0-14 years), clinically suspected of UTI, were processed in the Department of Microbiology for 3 years. Urine samples were collected in a sterile container and processed by inoculating on cysteine lactose electrolyte deficient agar (CLED). Antibiogram was performed by disc diffusion method as per CLSI guidelines. Gram-negative isolates were studies for expended spectrum $\beta$-lactamase (ESBL) production and $S$. aureus isolates were screened for methicillin-resistant S. aureus (MRSA).

Results: Out of 1492 samples, $876(58.7 \%)$ were found to be culture positive. Gram-negative bacteria (80.4\%) comprised the maximum number of isolates. E. coli $(60.7 \%)$ was the most frequently isolated uropathogen, followed by $K$. pneumoniae $(13.2 \%)$ and $S$. aureus (11.2\%). Twenty-one per cent of $E$. coli and $17.4 \%$ of $K$. pneumoniae were ESBL producers. Among S. aureus, $32.6 \%$ were MRSA.

Conclusion: High-level antimicrobial resistance was observed in pediatric UTI. We should adopt antimicrobial use based on local epidemiological data which helps in maximizing clinical outcome.

Key Words: E. Coli, ESBL, MRSA, Pediatric UTI

\section{INTRODUCTION}

Urinary tract infection (UTI) is one of the leading cause of febrile illness and hospital admission in the pediatric population. ${ }^{1}$ The global prevalence of pediatric UTI is approximately $2-20 \%{ }^{2}$ and up to $7 \%$ of girls and $2 \%$ of boys experience at least 1 episode of UTI before the age of $6 .^{3}$ It is more common in boys $(3.7 \%)$ than in girls $(2 \%)$ in the first year of life ${ }^{4}$ and thereafter, it has been reported to be more prevalent in girls except for uncircumcised boys younger than age 5. ${ }^{5}$ Pediatric UTI most often presents with non-specific signs and symptoms due to which it remains under-diagnosed in many cases. ${ }^{6}$ Part of the challenge in diagnosing is because of children having difficulty expressing their symptoms ${ }^{7}$ Vesicoureteric reflux (VUR) is the most common predisposing factor for UTI in children which further leads to complications like chronic pyelonephritis and eventual renal scarring, hypertension and chronic renal failure. So, UTI itself may be the sentinel event for underlying renal abnormality. ${ }^{8}$ Hence, timely diagnosis and treatment may prevent renal damage. Currently, the American Academy of Pediatrics (AAP) recommends that UTI be considered in any infant or child between two months and two years of age presenting with fever without an identifiable source of infection. ${ }^{9}$ Older children may present with the classic symptoms of UTI, i.e., dysuria, frequency, abdominal or flank pain and fever. ${ }^{7}$ Escherichia coli, by far the most common uropathogen, is also the commonest in pediatric UTIs. Other offending pathogens include Klebsiella spp., Proteus spp., Pseudomonas aeruginosa and

Corresponding Author:

Dr. Suren Kumar Das, Mch (Urology), Professor \& HOD, Department of Urology, IMS and SUM Hospital, Siksha "O” Anusandhan University (Deemed to be), K8 Kalinga Nagar, Bhubaneswar-751003, Odisha, India; Email: suren_bam@yahoo.co.in

ISSN: 2231-2196 (Print) ＩSSN: 0975-5241 (Online)

Received: $18.09 .2020 \quad$ Revised: 22.10 .2020

Accepted: 20.11 .2020

Published: 05.01 .2021 
Enterococcus spp..$^{10}$ There is a growing concern about antimicrobial resistance worldwide. Availability of scanty data of the resistance pattern of pediatric uropathogens in Eastern India prompted us to take the present study. The present study aimed to identify the bacterial pathogens involved in pediatric UTI and study their antibiogram patterns.

\section{MATERIALS AND METHODS}

This cross-sectional study was conducted in the Department of Microbiology, IMS \& SUM Hospital, Bhubaneswar, for a period of 3 years (March 2017- March 2020). A total of 1492 non-repetitive urine specimens of pediatric patients (0-14 years), clinically suspected of UTI were included in the study.

\section{Sample collection}

Urine samples were obtained by mid-stream clean catch in older children or children who were toilet trained. Nappy pad method was used for neonates, infants and toddlers. The pad was inserted into the nappy then removed as soon as the child urinated to reduce the risk of contamination. Once the nappy pad was removed, the urine was extracted with a syringe into a sterile container. ${ }^{11}$ In catheterized children, urine specimen was collected either through the catheter collection port or through puncture of the tubing with a sterile needle. ${ }^{12}$ The sample was then transported to the laboratory.

\section{Sample processing in the laboratory}

The urine samples were processed by semi-quantitative streaking method using a calibrated $1 \mu 1$ inoculating loop holding $0.001 \mathrm{ml}$ of urine onto cysteine lactose electrolyte deficient agar (CLED). The inoculated plates were incubated at $37^{\circ} \mathrm{C}$ for $24-48 \mathrm{hrs}$ at ambient air. The isolates were identified using standard microbiological methods like colony morphology, gram stain and a set of biochemical tests. Antibacterial susceptibility test (ABST) was performed using the Kirby-Bauer disc diffusion method on Mueller Hinton agar (MHA) as per clinical laboratory standards institute (CLSI) guidelines. ${ }^{13}$

Gram-negative isolates if found resistant to third-generation cephalosporins on ABST were considered as potential extended-spectrum $\beta$-lactamases (ESBL) producers and confirmed by the combined disc test method. In this method, the suspected isolate was tested against ceftazidime alone and ceftazidime + clavulanic acid combination disc. Isolate showing the increase in the zone of inhibition of $\geq 5 \mathrm{~mm}$ of the combination disc in comparison to that of ceftazidime alone was considered as ESBL producer.

All S. aureus isolates were screened for methicillin-resistant Staphylococcus aureus (MRSA) by using cefoxitin disc. Isolate showing a zone size of $\leq 22 \mathrm{~mm}$ was considered as MRSA.

\section{Laboratory analysis}

Positive urine culture was defined as $\geq 10^{3}$ colonies forming unit $(\mathrm{CFU}) / \mathrm{ml}$ for suprapubic specimen, $\geq 10^{4} \mathrm{CFU} / \mathrm{ml}$ for catheterized specimen and $\geq 10^{5} \mathrm{CFU} / \mathrm{ml}$ for clean catch specimen.

\section{RESULTS}

A total of 1492 non-repetitive urine samples were obtained from children with suspected UTI during the study period (March 2017- March 2020).

Among 1492 children, 813 (54.5\%) were girls and 679 (45.5\%) were boys. The maximum number of cases belonged to children of 0-5 years $(638 / 1492,42.8 \%)$ age group. (Table 1$)$.

$\begin{aligned} & \text { Table 1: Age and gender distribution of pediatric UTI } \\
& \text { cases }\end{aligned}$
\begin{tabular}{lccc} 
Age Group (Years) & Girls & Boys & Total (N/\%) \\
\hline 0-5 & 296 & 342 & $638(42.8 \%)$ \\
$6-10$ & 144 & 221 & $365(24.5 \%)$ \\
$11-14$ & 373 & 116 & $489(32.7 \%)$ \\
Total & 813 & 679 & $1492(100 \%)$ \\
\hline
\end{tabular}

Out of 1492 children with suspected UTI, 876 (58.7\%) were found to be culture-positive yielding significant bacteriuria. Gram-negative bacteria $(80.4 \%)$ was more frequently isolated than Gram-positive bacteria (17.5\%). Candida was recovered in $2.1 \%$ of the isolates. E. coli was the most common uropathogen isolated followed by $K$. pneumoniae. (Table 2)

Table 2: Distribution of isolated uropathogens:

ORGANISMS $(\mathrm{n}=876) \quad$ FREQUENCY PERCENTAGE

GRAM NEGATIVE BACTERIA

\begin{tabular}{lcc} 
Escherichia coli & 532 & $60.7 \%$ \\
Klebsiella pneumonia & 115 & $13.2 \%$ \\
Proteus spp. & 34 & $3.9 \%$ \\
$\begin{array}{l}\text { Pseudomonas aeruginosa } \\
\text { GRAM POSITIVE BACTERIA }\end{array}$ & 23 & $2.6 \%$ \\
$\begin{array}{l}\text { Staphylococcus aureus } \\
\text { Coagulase negative Staphy- }\end{array}$ & 98 & $11.2 \%$ \\
lococci (CoNS) & 43 & $4.9 \%$ \\
Enterococcus spp. & 12 & $1.4 \%$ \\
BUDDING YEAST CELL & & \\
Candida tropicalis & 9 & $1 \%$ \\
Candida parapsilosis & 6 & $0.7 \%$ \\
Candida albicans & 3 & $0.3 \%$ \\
Candida glabrata & 1 & $0.1 \%$ \\
\hline
\end{tabular}


Antimicrobial susceptibility test showed variable degree of resistance. Majority of E. coli isolates were most susceptible towards netilmicin $(94.4 \%)$, amikacin $(88.1 \%)$ and minocycline $(77 \%)$ and least susceptible towards norfloxacin $(12.6 \%)$, cotrimoxazole $(21.2 \%)$ and cefixime $(21.6 \%)$ as shown in graph 1. Out of 532 isolates of E. coli, $112(21 \%)$ were ESBL producers (Figure 1).

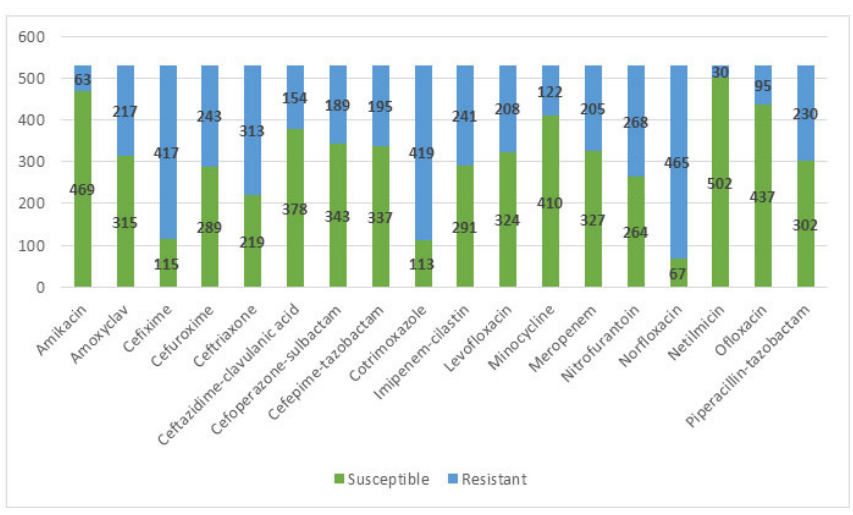

Figure 1: Antibiogram of E. coli: $(n=532)$.

Isolates of $K$. pneumoniae were most susceptible towards ceftazidime-clavulanic acid (57.4\%), minocycline (54.8\%) and meropenem (51.3\%) and least susceptible towards amoxiclav (14.8\%), cefixime (22.6\%) and imipenem-cilastatin $(23.5 \%)$ as shown in Graph 2. Twenty isolates (17.4\%) of $K$. pneumoniae were ESBL producers.

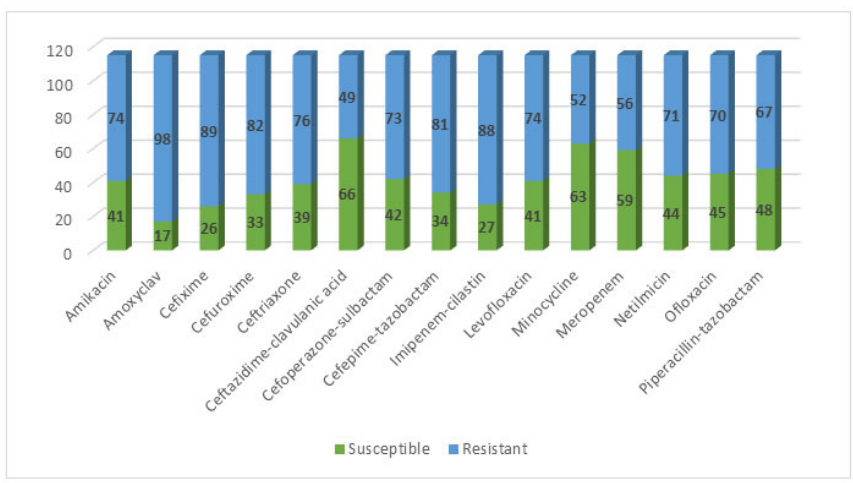

Figure 2: Antibiogram pattern of K. pneumoniae: $(n=115)$.

Isolates of $S$. aureus were most susceptible towards linezolid and vancomycin $(100 \%$ each) and least susceptible towards clarithromycin (10.2\%), cefixime (22.4\%) and moxifloxacin $(27.5 \%)$ as shown in graph 3. Thirty-two (32.6\%) isolates of S. aureus were MRSA.

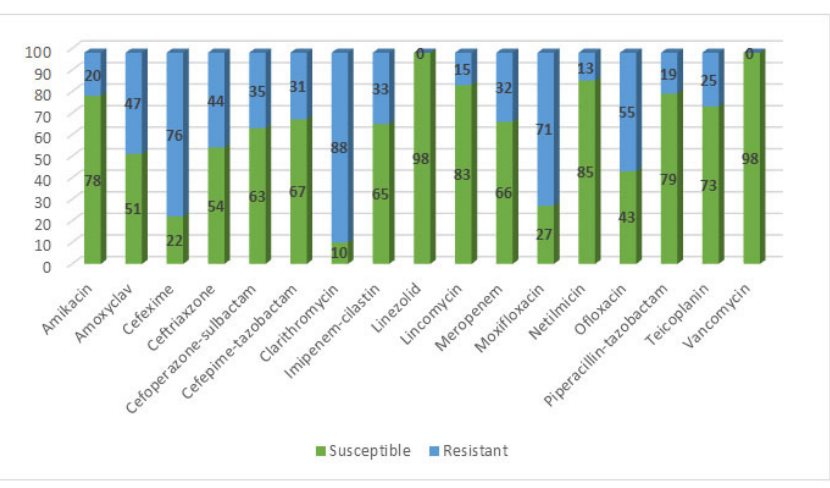

Figure 3: Antibiogram pattern of $S$. aureus: $(n=98)$.

\section{DISCUSSION}

UTI is a common health problem and an important cause of morbidity and mortality in children. In the present study, $58.7 \%$ of the total samples were positive for UTI. In contrast, studies done by Badhan et $a l^{14}$ and Gupta et $a l^{4}$ in India showed a lower culture positivity (26.7 and $35.4 \%$ respectively) whereas global estimates of pediatric UTI are much lower, i.e., $7.87 \%$ in $\operatorname{Iran}^{15}$ and $9 \%$ in the USA. ${ }^{16}$

The most common organism associated with pediatric UTI in this study was E. coli (60.7\%) with K. pneumoniae being the second most common uropathogen, which is in concordance with many other studies. ${ }^{4,14,17}$ Irrespective of age, sex, community or country, E. coli is the most common uropathogen. Although Gram-negative bacteria comprise the majority of UTI cases, Gram-positive organisms have become an important cause in recent years. In this study, $11.2 \%$ of UTI cases were due to $S$. aureus, which was also the third most common organism isolated. This finding is consistent with other studies. ${ }^{18,19}$

In this study, we have found decreased susceptibility of uropathogens towards nitrofurantoin, cephalosporins, fluoroquinolones and carbapenems and better efficacy of aminoglycosides in vitro. Only $49.6 \%$ of $E$. coli were susceptible to nitrofurantoin, $21.2 \%$ to cotrimoxazole, $21.6 \%$ to cefixime and $12.6 \%$ to norfloxacin. This is the most alarming finding of our study pointing towards the prevalence of multidrugresistant organisms (MDROs) in the pediatric population. Also, $21 \%$ of $E$. coli and $17.4 \%$ of $K$. pneumoniae were ESBL producers. Similar results were reported by Baral et a ${ }^{19}$ and Parajuli et al. ${ }^{20}$ Pediatric UTI with ESBL producing organisms pose a threat in treatment by limiting therapeutic choices.

Among Gram-positive organisms, $32.6 \%$ of $S$. aureus were MRSA; $22.4 \%$ were susceptible to cefixime, $27.5 \%$ to moxifloxacin and $10.2 \%$ to clarithromycin but showed fair susceptibility towards cephalosporin combination with a betalactamase inhibitor. Similar findings were reported by Gupta 
et al ${ }^{4}$ and Looney et al. ${ }^{21}$ Previous hospitalization, long-term broad-spectrum antimicrobial therapy, co-morbidity, frequent instrumentation, catheterized patients might explain the higher antimicrobial resistance.

\section{CONCLUSION}

E. coli continues to be the predominant uropathogen causing UTI in children. MDROs, ESBL and MRSA are on the rise in the pediatric population. Also, this study highlights the better efficacy of aminoglycosides in vitro in comparison to other commonly used classes of drugs. We should adopt antimicrobial use based on local epidemiological data which helps in maximizing clinical outcome.

\section{ACKNOWLEDGEMENT}

Authors acknowledge the immense help received from the scholars whose articles are cited and included in references to this manuscript.

\section{Conflict of Interest: Nil}

Source of Funding: Nil

\section{REFERENCES}

1. Shaikh N, Morone NE, Bost JE, Farrell MH. Prevalence of urinary tract infection in childhood: a meta-analysis. Pediatr Infect Dis J 2008;27:302-8.

2. Downing H, Thomas-Jones E, Gal M, Waldron CA, Sterne J, Hollingworth W, et al. The diagnosis of urinary tract infections in young children (DUTY): protocol for a diagnostic and prospective observational study to derive and validate a clinical algorithm for the diagnosis of UTI in children presenting to primary care with an acute illness. BMC Infect Dis 2012;12:158.

3. Mårild S, Jodal U. Incidence rate of first-time symptomatic urinary tract infection in children under 6 years of age. Acta Paediatr 1998;87:549-52.

4. Gupta P, Mandal J, Krishnamurthy S, Barathi D, Pandit N. Profile of urinary tract infections in pediatric patients. Indian J Med Res 2015;141:473-7.

5. Dahiya A, Goldman RD. Management of asymptomatic bacteriuria in children. Canadian Fam Physic 2018;64:821-3.

6. Desai DJ, Gilbert B, McBride CA. Paediatric urinary tract infections: diagnosis and treatment. Aust Fam Physic 2016;45:55863.

7. Bitsori M, Galanakis E. Pediatric urinary tract infections: diagnosis and treatment. Expert Rev Anti Infect Ther 2012;10:115364.
8. Aggarwal V K, Ferrier V, Jones K. Vesicoureteric reflux: screening of first degree relatives. Arch Dis Child 1989;64:1538-41.

9. Roberts KB. Urinary tract infection: clinical practice guideline for the diagnosis and management of the initial UTI in febrile infants and children 2 to 24 months. Paediatrics 2011;128:595610 .

10. Marcus N, Ashkenazi S, Yaari A, et al. Non-Escherichia coli versus Escherichia coli community-acquired urinary tract infections in children hospitalized in a tertiary centre. Pediatr Infect Dis J 2005;24:581-5.

11. Liaw LC, Nayar DM, Pedler SJ, Coulthard MG. Home collection of urine for culture from infants by three methods: survey of parents' preferences and bacterial contamination rates. BMJ 2000;320:1312-3

12. Hooton TM, Bradley SF, Cardenas DD, Colgan R, Geerlings SE, Rice JC, et al. Diagnosis, prevention, and treatment of catheterassociated urinary tract infection in adults: 2009 international clinical practice guidelines from the Infectious Diseases Society of America. Clin Infect Dis 2010;50:625-63.

13. CLSI. Performance standards for antimicrobial susceptibility testing. 27th ed. CLSI supplement M100. Wayne, PA: Clinical and Laboratory Standards Institute; 2017

14. Badhan R, Singh DV, Badhan LR, Kaur A. Evaluation of bacteriological profile and antibiotic sensitivity patterns in children with urinary tract infection: a prospective study from a tertiary care centre. Indian J Urol 2016;32:50-6.

15. Zorc JJ, Levine DA, Platt SL, Dayan PS, Macias CG, Krief W, et al. Clinical and demographic factors associated with urinary tract infection in young febrile infants. Paediatrics 2005;116:644-8.

16. Mirsoleymani SR, Salimi M, Shareghi Brojeni M, Ranjbar M, Mehtarpoor M. Bacterial pathogens and antimicrobial resistance patterns in pediatric urinary tract infections: a four-year surveillance study. Int J Pediatr 2014;6.

17. Singh SD, Madhup SK. Clinical profile and antibiotics sensitivity in childhood urinary tract infection at Dhulikhel hospital. Kathmandu Univ Med J (KUMJ). 2013;11:319-24.

18. Kaur N, Sharma S, Malhotra S, Madan P, Hans C. Urinary tract infection: aetiology and antimicrobial resistance pattern in infants from a tertiary care hospital in northern India. J Clin Diagn Res 2014;8:DC01-3.

19. Baral P, Neupane S, Marasini BP, Ghimire KR, Lekhak B, Shrestha B. High prevalence of multidrug resistance in bacterial uropathogens from Kathmandu, Nepal. BMC Res Notes 2012;5:38.

20. Parajuli NP, Maharjan P, Parajuli H, Joshi G, Paudel D, Sayami $\mathrm{S}$, et al. High rates of multidrug resistance among uropathogenic Escherichia coli in children and analyses of ESBL producers from Nepal. Antim. Resist Infect Control 2017;6:9.

21. Looney AT, Redmond EJ, Davey NM, Daly PJ, Troy C, Carey BF, et al. Methicillin-resistant Staphylococcus aureus as a uropathogen in an Irish setting. Med J 2017;96(14):e4635. 